\title{
THE POST-NATAL WEIGHT LOSS OF BABIES BORN TO DIABETIC AND NON-DIABETIC WOMEN
}

BY

\author{
JAMES W. FARQUHAR and STANLEY A. SKLAROFF \\ From the Departments of Child Life and Health and of Public Health and Social Medicine, University of Edinburgh, and \\ the Simpson Memorial Maternity Pavilion, Royal Infirmary, Edinburgh
}

(RECEIVED FOR PUBLICATION FEBRUARY 26, 1958)

The fact that babies of diabetic women are heavier as a group than those born at the same gestational age to non-diabetic women has been attributed in part to foetal oedema. Apart from their oedematous appearance, however, such infants are said to lose more weight in the immediate newborn period than babies of healthy women, and it has been concluded that this is the result of water loss. The object of the present paper is to review the evidence for a significant difference in post-natal weight loss between the babies of diabetic and non-diabetic mothers, and to present the results of a comparative study of postnatal changes in weight with special reference to the type of 'normal' babies used as controls.

\section{Evidence for Weight Loss}

Oedema. The greater weight of babies born to diabetic women has been ascribed by White (1952) to fat, visceral enlargement and fluid retention. She considered that the babies were often oedematous, and she believed that a diuresis was responsible for the abnormal weight loss. This opinion is reflected in such well-known textbooks as those of Baird (1950), Grulee and Eley (1952), Nelson (1954), Johnstone and Kellar (1955), Ellis (1956), Price (1956) and Dunlop, Davidson and Alstead (1958). According to White the oedema may be made to pit on pressure, but Gellis (1954) described it as non-pitting. This difference of opinion is of the greatest importance because if White is correct then the diagnosis of oedema cannot be doubted. If the oedema cannot be demonstrated by pitting, however, then the diagnosis cannot be confirmed without such direct evidence as may be obtained by measurement of the body water or by careful records of body weight and fluid balance. As White and Gellis have probably shared a number of their cases and have discussed them together (Gellis, White and Pfeffer, 1949) the wide divergence of opinion between two such acknowledged authorities indicates that doubt exists about the presence of pitting oedema.
Diuresis. Although a number of papers mention the occurrence of a diuresis in such babies, no real proof of its occurrence has been provided, and no record of a fluid balance study has been found. In a previous paper Farquhar (1956) measured the 24hour urine volumes of infants born to diabetic and to non-diabetic women. The former babies received no fluid during the first 72 hours, but each passed on average about $60 \mathrm{ml}$. more urine during the first 48 hours than the control babies who were fed from the first day of life. During the third day there was little difference between the urine volumes of the two groups. The groups were small and they were not comparable with regard to maturity or the route of delivery, but the results strongly suggested that babies of diabetic women pass rather more urine initially than normal babies. The difference in volume, however, was so small that it could not be responsible for much difference in weight loss between the groups.

Weight Loss. The studies of White (1952) and Cardell (1953) on the post-natal weight loss of infants born to diabetic mothers are well known. Although White has the larger series her analysis of the subject is less satisfactory than is that of Cardell. Her description of the amount of weight lost does not prove that this was abnormal. She did not define what she meant by weight loss and she provided no information about the control group other than that the mothers were non-diabetic women who had been delivered at the same hospital over the same time interval. She compared only the average weight loss of the two groups and even this was in terms of absolute weight and made no allowance for the greater birth weight or different maturity of the babies of diabetic women. The babies in Cardell's study were grouped first according to birth weight. He was then able to show that infants of diabetic women in his series lost significantly more weight (expressed as a percentage of birth weight) than 
'control babies' of comparable birth weight. He failed to define what he meant by weight loss, although he clearly did not mean the weight loss over a fixed time interval. He gave no idea of the variability of weight loss. His control group did not match his diabetic group with regard to either maturity or the route of delivery. Neither White nor Cardell provided any detail about the technique of weighing, the environmental conditions under which their diabetic and control series were nursed or how and when they were fed.

The Problem. Because the evidence in favour of foetal oedema is inconclusive, it was decided to examine in greater detail the post-natal weight loss of babies born to diabetic and non-diabetic women.

Most of the infants in the Edinburgh series, like those delivered in the hospitals from which both White and Cardell have published their papers, have been delivered by Caesarean section. It was decided to compare the weight loss of the diabetic group not only with that of infants delivered spontaneously to non-diabetic women but also with that of babies born by Caesarean section to non-diabetic women.

The diabetic group has been subdivided into two according to the feeding history. Between the years 1948 and 1951 most of these babies were fed early because of a fear that they might suffer from hypoglycaemia. When it became recognized that this was not harmful and that inhalation occurred rather easily on the first and second days, feeding was delayed in those infants born during the years 1952 to 1955.

Consideration has been given to the comparability of the groups and also to the environmental conditions in which the infants were nursed.

\section{Composition of Groups}

A. Diabetic Mothers. The infants of diabetic mothers delivered by Caesarean section during the years 1948-55 are divided into two groups, one of which (A1) consists of 31 babies who were fed within the first 24 hours. The second group (A2) consists of 29 infants who were unfed until aged 72 hours for the reasons already given.

B. Non-Diabetic Mothers. The infants of nondiabetic mothers are divided into two groups, one of which (B1) consists of 60 babies born by Caesarean section to women who had not been in labour before operation. The second group (B2) consists of 60 babies born spontaneously by the vertex per vaginam. These two groups are matched with one another for maternal age and parity.

The mothers of infants in group B1 were delivered in the years 1948-49 and 1953-54. They had Caesarean sections performed because of placenta praevia in almost half the cases, because of pregnancy toxaemia in less than one sixth, and because of disproportion or previous uterine scar in the remainder. So that they might be compared in ways other than those mentioned in this paper, as many as possible of the cases were of 36 to 38 weeks' gestation.

Infants in both groups B1 and B2 were fed during the first 24 hours. Those in group B1 usually received a bottle, whereas those in group B2 were put to the breast. Infants were excluded from groups B1 and B2 if they died later during the newborn period or if they had lost blood, were pyrexial or had any congenital malformation, infection or gastrointestinal disorder which was considered by the clinician to have a possible influence upon the weight behaviour.

\section{Comparability of Groups}

Sex, maternal age, social class (husband's occupation), parity, birth weight and maturity have all been shown to be relevant to birth weight. It was not known to what extent these would also affect weight loss, but since they were readily available they were all taken into account. It was clearly impossible to match the groups according to all these criteria, but where possible maternal age and parity were selected for matching.* These are accepted as being of fundamental importance in birth weight studies. The other characteristics are also presented for comparison.

A. Diabetic Groups. Because these groups formed the consecutive halves of a naturally occurring series no previous matching according to the above criteria was possible. The two groups are evenly balanced for foetal sex, and there is no marked difference in parity. Group A2 contains rather more babies in higher social classes than group A1 (Fig. 1). There are rather more of the heavier babies in group A1 than in A2 because of the greater variability of birth weight in A1. There is also greater variation in the maturity of infants in group A1, so that the group contains relatively larger numbers of more mature infants than does group A2. The lower birth weight and lesser maturity of infants in group A2 reflects the adoption of a more rigid policy about Caesarean section at the 36 th-37th week which was adopted about 1951 .

\footnotetext{
* No relationship between the infants' weight loss and maternal age or parity was found by Naish and Edwards (1952) in their study of normal babies. It was decided, however, that for the better comparison of these abnormal and normal groups these two factors should be taken into account.
} 
B. Non-Diabetic Groups. The spontaneous deliveries (B2) were matched with the non-diabetic Caesarean deliveries (B1) for maternal age and parity (Fig. 1). The two groups are evenly balanced for foetal sex. Rather more of the infants in group B1 are of social classes IV and V. There is no marked difference in birth weight, but the babies in group B1 are distinctly less mature.

DiabeTIC AND NonDiabetic Groups. As a result of the comparative infrequency with which Caesarean section is carried out prematurely in the nondiabetic woman, the number of babies available for inclusion in this group was rather limited, and it was found impossible to match them for maternal age and parity with either diabetic group. Older women make up a greater proportion of the non-diabetic Caesarean group (B1) than in either A1 or A2, but there is less difference in parity. Birth weight is less scattered in the non-diabetic Caesarean group (B1) but the maturity is more evenly spread over the period 36 to 40 weeks than in the diabetic groups. It may be seen from Fig. 1 that the infants of group B2 are clearly more mature than those of group $B 1$, which in turn are more mature than those of groups $\mathrm{A} 2$ and $\mathrm{A} 1$.

\section{Environmental Conditions During the Period of Measurement}

The babies of the diabetic groups were nursed nude in premature rooms at a temperature of $80^{\circ} \mathrm{F}$. Those in group A1 were moved to the main nursery after 2-3 days, and those in group A2 graduated there on the fourth or fifth day. Only a small proportion of the babies in group B1 (non-diabetic Caesarean controls) was admitted to the premature room and then usually for no longer than 24 hours. Most of them were retained in the main nursery at an environmental temperature of $70^{\circ} \mathrm{F}$. and normal humidity. The babies of group B2 (spontaneous

NORMAL

WAGINALOU

VAGINAL
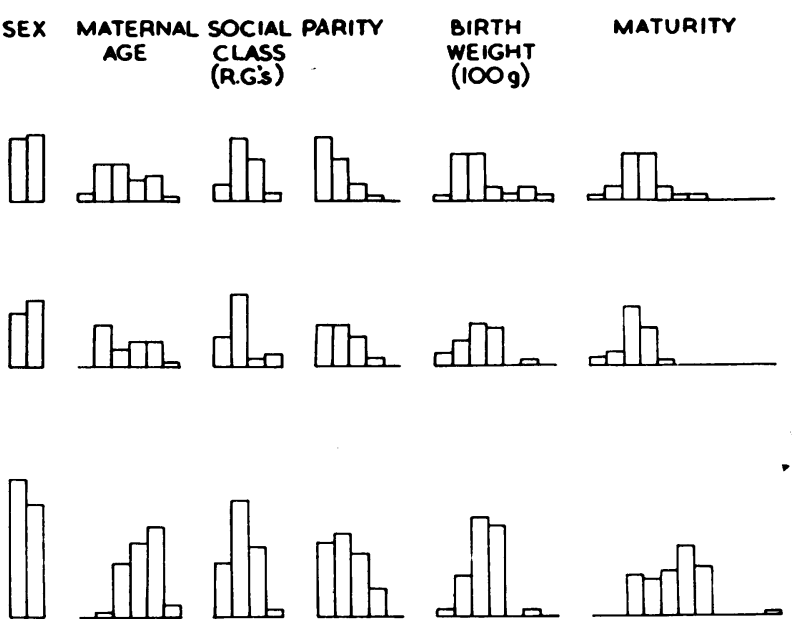

DELIVERIES
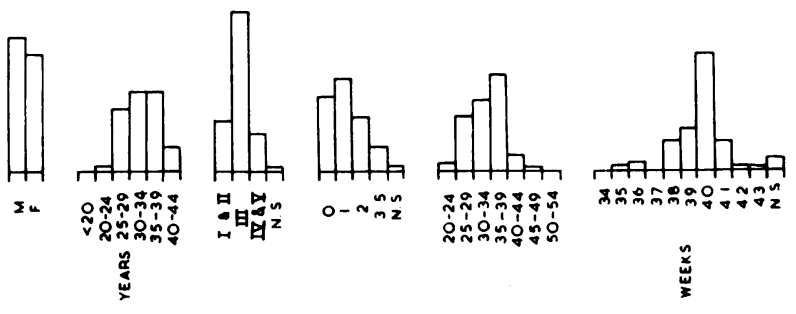

N.S = NOT STATEO

FIG. 1.-Comparison of the groups.

deliveries) were admitted to the main nursery from the labour ward. In the nursery all infants wore a napkin and gown. They were rolled in a cotton sheet and blanket and covered by one blanket and a light cotton coverlet.

\section{Method of Weighing}

All the babies have been weighed naked on Avery scales which are tested regularly and which are accurate to $\frac{1}{4} \mathrm{oz} .(7 \cdot 1 \mathrm{~g}$.). They are weighed on arrival from the labour room and at the same hour each morning thereafter. The majority of babies in groups A1, A2 and B1 were born in the forenoon by elective Caesarean section. The beginning of the second day on the weight chart therefore corresponded to an age of about 22 hours. Unfortunately in group B2 the actual age at the beginning of the second day on the chart ranged from eight to about 30 hours. The retrospective nature of the study made this unavoidable. Weights were graphed on the infant charts and the plotting of the points was found to be accurate to about $\frac{1}{2} \mathrm{oz}$. $(14 \cdot 2 \mathrm{~g}$.) when com- 
pared with the written record. The weights of the infants in group B2 were recorded daily from birth. This applied also to the great majority of babies in group B1. In groups A1 and A2, however, the weight records during the first 48 hours were incomplete at times as some infants were nursed with the minimum of disturbance, and others were attached to experimental apparatus the efficiency of which would have been prejudiced by movement or disconnection.

\section{Results}

Criteria of Weight Changes. In defining what is meant by weight changes the features to be considered are the time interval over which the alteration occurs and the weight change in either absolute or relative terms. In this paper the relative weight loss each day is expressed as a percentage of birth weight.

Percentage Weight Loss in Relation to Birth Weight. The relationship between percentage weight loss and birth weight has been examined for several of the days after birth. No association was discovered on any of these days, and Fig. 2 illustrates this lack of
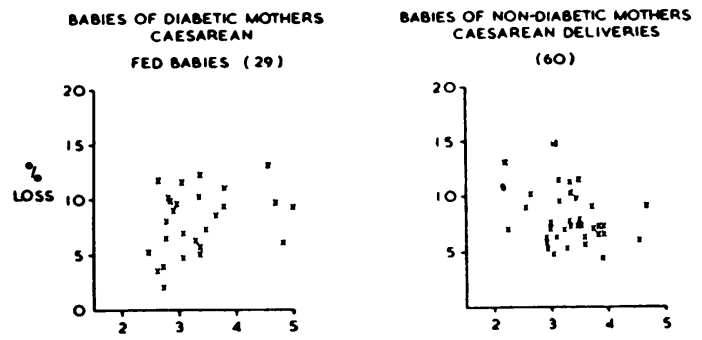
CAESAREAN DELIVERIES $(60)$

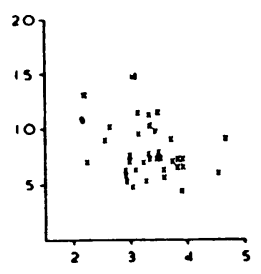

UNFED BABIES (31)

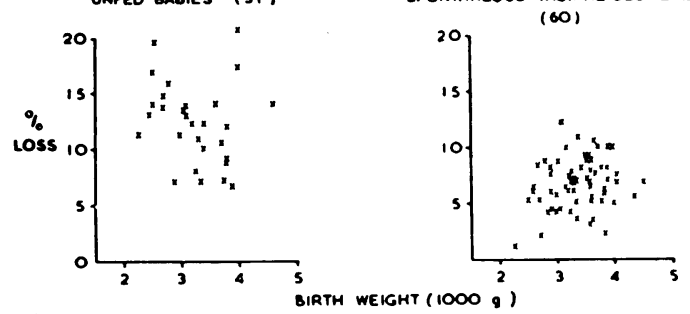

Fig. 2.-Post-natal weight loss on fourth day as a percentage of birth weight.

any relationship on the fourth day in all of the four groups. The variability of percentage weight loss changes with age. It is least at the third or fourth day after birth, and increases thereafter.

Method of Presentation. The individual weight record of each infant in the four groups has been studied and examples of the variability of individual
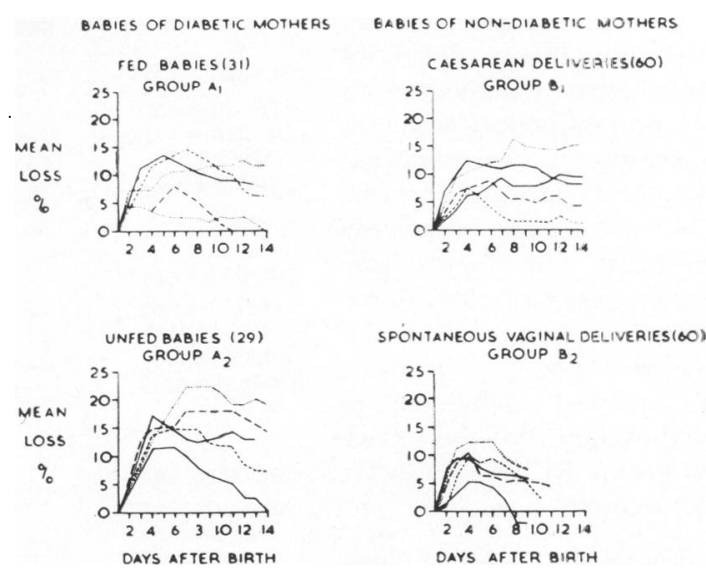

Fig. 3.-Examples of variation in post-natal weight loss in the four groups.

weight changes within each group are shown in Fig. 3. The main results, however, are presented as group averages with standard deviations (Fig. 4).

Group Differences in the Pattern of Weight Change (Fig. 4). (a) A significant difference in the pattern of weight change clearly exists between the two diabetic sub-groups. The unfed group (A2) loses more weight than the fed group (A1) and the rate of regain may be a little more rapid during the period up to 14 days.

(b) There were no significant differences in the trend of mean percentage weight changes between the fed diabetic Caesarean group (A1) and the nondiabetic Caesarean group (B1). The statistical significance of the differences between the means for each day after birth was assessed by Fisher's $F$ test
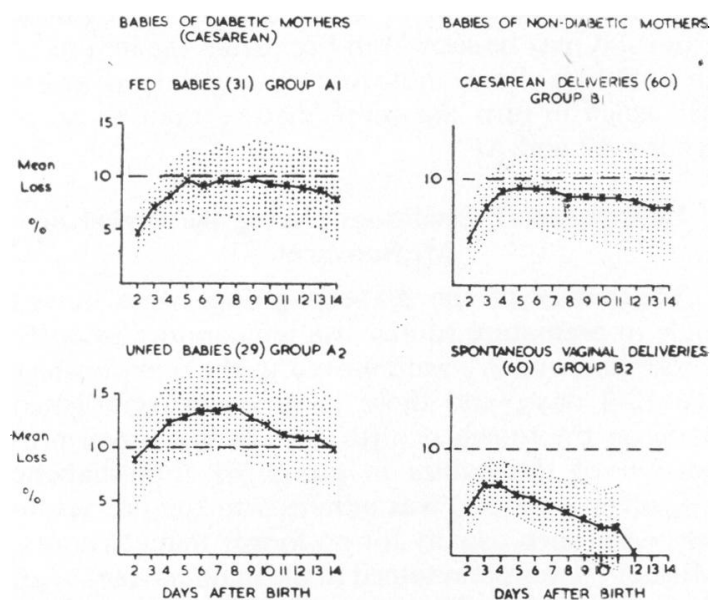

Fig. 4.-Group differences in the pattern of post-natal weight change. (Shading indicates \pm one standard deviation about the mean.) 
(Snedecor, 1956). In no case did the magnitude of the observed difference correspond with a probability of less than 1 in $5(\mathrm{p}>\cdot 2)$ of occurrence by chance in random sampling from a common population.

Although the percentage weight losses of the nondiabetic Caesarean group were slightly more variable than those of the fed diabetic group, there was no significant difference in their respective variability up to the 11 th day as assessed by the $F$ test.

(c) A significant difference in the pattern of weight change clearly exists between those of all the Caesarean groups (A1, A2 and B1) and that of the spontaneous group (B2). The latter loses less weight, and an earlier and more rapid regain of weight occurs.

\section{Discussion}

The newly born infant of the diabetic woman commonly has a puffy, sometimes even a bloated appearance which he loses during the first week of life. This puffiness has been attributed to oedema partly because it 'looks like oedema', partly because it changes so quickly, but mostly because pitting oedema has been demonstrated in some cases. The shedding of this fluid has been taken as the explanation of the apparent excessive post-natal weight loss. As we have stated already the babies were found by White (1952) to have pitting oedema, yet the same infants were found by Gellis (1954) to have nonpitting oedema. Neither author mentioned any exception. Oedema was accepted as the explanation of the appearance of such infants by the clinician in the Edinburgh series of over 100 cases. The baby charts appeared to show abnormal post-natal weight losses, but pitting oedema was rare and 'occult oedema' was assumed in the majority. In the second half of 1957 not one of 10 such babies showed convincing pitting oedema, although most of them were described as 'puffy' or 'flabby'. The largest of these weighed $5.0 \mathrm{~kg}$. when delivered at the 36th week of gestation. He was stated by a midwife to have shown pitting oedema at birth, but when examined at three hours by one of us no evidence of it could be found. The greatest percentage weight loss of the 10 occurred in a baby who had shown no pitting oedema at birth and in whom even the characteristic puffy appearance was missing.

Direct measurement of the urine volume during the first 48 hours of life, however, showed that a group of babies born to diabetic mothers passed an average of only $60 \mathrm{ml}$. more urine than more mature infants born to non-diabetic mothers, and by the third day the urine volumes of the two groups were similar (Farquhar, 1956). Although this did in fact mean that the infants of the diabetic group passed three times as much urine on average as those of the non-diabetic group, such a difference would add comparatively little to the weight loss of infants in the diabetic group. Unless such babies lose relatively greater amounts of fluid from the skin, the lungs or the bowel, and no evidence of this has been reported, then some other explanation of their reported greater weight loss must be sought. In the first place the criteria and the consistency of weight loss should be examined.

Criteria and Consistency of Weight Loss. When it is remembered that the birth weights of infants born to diabetic women are often above average, it is clear that if their weight loss is to be compared in terms of absolute weight with that of infants born to non-diabetic women then the birth weights of the two groups must be given. This was not done by White (1952) who gave only the average absolute weight loss of the two groups. A proper comparison can be made only when the weight loss of each infant in the groups is expressed on each day as a percentage of birth weight. Although Cardell (1953) did express the weight losses of his diabetic and control groups in such relative terms he did not specify what he meant by weight loss. He probably did not take the amount of weight lost over a fixed time interval, such as from birth to the fourth day, and it may be assumed that he selected the maximum amount of weight lost irrespective of the time interval. A study of individual weight patterns in the present groups, however, has shown how difficult the selection of 'the point of maximum weight loss' may be. Quite commonly the regain of weight which follows the initial loss is interrupted by a further fall in weight which may be the result of inadequate feeding, infection or some unrecognized factor. The present paper shows the variability of individual weight patterns, but the means and standard deviations for each day and for each group have also been calculated and compared.

Comparability of Diabetic and Control Groups. The control cases recorded by both White and Cardell were born spontaneously and were usually some weeks more mature than their infants in the diabetic groups, most of which were delivered by Caesarean section. The possible influence of maternal age and parity was not considered in either. For these reasons their control cases were imperfect and it was decided that in the present investigation the diabetic groups would be compared with two groups of infants, one of which had been delivered spontaneously, and the other by Caesarean section, to non-diabetic mothers. Lack of knowledge about the exact age in hours of the present vaginal delivery group at the time of weighing probably makes very 
little difference to the group's general pattern of weight loss. The retrospective study of Naish and Edwards (1952) suffers from the same defect. The average weight loss increases to $6 \cdot 7 \%$ of birth weight by the fourth day, and from then steady regain of weight occurs. The pattern is similar to that described by Gregory (1871), Holmes (1896), Griffith and Gittings (1907) and Kotz and Kaufman (1939) and it is quite different from that of any of the Caesarean section groups.

If the percentage of birth weight lost were to increase as birth weight increases then group comparison of relative loss would be possible only if the groups were evenly matched with regard to birth weight. For this reason the relationship of birth weight to the percentage of birth weight lost was studied for each of the present groups, and no correlation whatsoever was found. This finding opposes that of Griffiths and Gittings (1907) but confirms that of Naish and Edwards (1952) with regard to vaginal deliveries, and extends the observation to infants delivered by Caesarean section either to diabetic or non-diabetic mothers.

Delayed Feeding. The influence of delayed feeding upon the weight of the newborn baby has been studied by Griffith and Gittings (1907) and by Rott (1910). They demonstrated that the less fluid an infant receives during the first three days the more weight he will lose. The giving or withholding of extra fluid before lactation was established was believed to have been responsible for either an increase or a decrease respectively in the weight loss of infants studied by Naish and Edwards (1952) and the time of the first feed was found by Salber and Bradshaw (1954) to influence subsequent weight behaviour. The withholding of fluids until after 72 hours in group A2 was expected to influence weight loss, and the likelihood of this was increased by the high environmental temperatures in which these babies were nursed. This group did in fact lose more weight than group $A 1$, the infants of which received fluids on the first day and were moved to a cooler nursery after 24 hours. Infants which have been dehydrated by simple water deprivation will regain weight quickly when fluids are given and this may explain why group A2 regained weight a little more rapidly than group $\mathrm{A} 1$.

Foetal Maturity. Although the greater weight loss and slower weight regain of group B1 when compared with group B2 is associated with the lesser maturity of group B1, the slightly greater maturity of group B1 when compared with group A2 is not associated with a similar difference in group pattern of weight loss. The small immature baby is said by Smith (1951) to lose a greater percentage of its birth weight than the mature infant, because the less mature the baby and the lower his birth weight the longer will feeding be deferred. The present study strongly suggests that deferred feeding and possibly environmental temperature exert a considerable influence on weight loss. There is no clear indication that differences in maturity alone explain the wide differences between the two non-diabetic groups, but if there is an association between maturity and the pattern of weight loss in the non-diabetic groups then this clearly does not extend to the diabetic groups.

Route of Delivery. The post-natal weight loss of infants delivered either spontaneously or by Caesarean section to non-diabetic women has been studied by Furuhjelm (1954). He subdivided his Caesarean section group into those women who had been in labour before operation and those who had not. When he compared his three groups he found that the mean weight loss of all three was equal by the third day, when it constituted about $7 \cdot 2 \%$ of birth weight. This corresponds closely to the behaviour of the two non-diabetic groups in the present paper. After the third day Furuhjelm's vaginal deliveries no longer lost weight, but both Caesarean section groups continued to lose weight for two more days. The group of infants who had been born by Caesarean section to labouring women then began to gain weight parallel to the vaginal group. The group of infants who had been born by Caesarean section to non-labouring women, however, gained weight much more slowly. This also corresponds to the behaviour of the two closely matched non-diabetic groups in the present paper.

\section{Conclusion}

Had the present study been concerned only with a comparison of the post-natal weight loss of babies born by Caesarean section to diabetic women and those delivered spontaneously to non-diabetic women, then agreement would have been achieved with White and with Cardell. The conclusion that the greater weight loss of the diabetic group was the result of shedding oedema would probably have been reached. The inclusion of a non-diabetic Caesarean section group and the effort made to match this with the vaginal group and to consider the other factors previously mentioned have altered the picture completely. No evidence has been found to confirm the belief that infants born by Caesarean section to comparable groups of diabetic and non-diabetic mothers differ significantly in their post-natal weight patterns. It cannot be said therefore that the exces- 
sive weight loss of infants born to diabetic women is evidence of their having been oedematous.

No explanation is offered for the striking difference in post-natal weight between babies delivered by Caesarean section to non-labouring women and those delivered after normal labour. It is true that lactation is established more slowly in the woman delivered by Caesarean section, and during the waiting period complementary feeds may be kept small in order that the infant's hunger might act as a stimulus to the breast.

The process of labour was considered by Furuhjelm to be responsible for the differences in weight pattern between Caesarean and spontaneous groups, but the underlying condition for which Caesarean section is performed may be responsible. Furuhjelm failed to specify why the Caesarean sections were carried out on his patients, but if this were the explanation then, in the present study, diabetes mellitus would appear to have no greater influence on the post-natal weight of the foetus than placenta praevia, disproportion or previous uterine scar, which were the principal reasons for section in the control Caesarean group.

When ligature of the cord is delayed until the placenta is expelled the infant received considerably more placental blood. According to Zweifel (1878) such babies lose less weight post-natally than those whose cords were cut immediately after delivery. The cord is of course likely to be clamped more rapidly after delivery by Caesarean section than by the vagina, but $Z$ weifel compared absolute weight losses, and his comparisons may not be valid.

Further studies will be required to explain this difference in weight behaviour, and in these the reason for Caesarean section, the nature of the labour, the time allowed to elapse before the cord is clamped, the maturity of the child and the details of feeding should be examined with greater care than has been possible in a retrospective study.

\section{Summary}

The abnormal heaviness of infants born to diabetic women has been ascribed in part to oedema.

The evidence in favour of the claims that because of this such infants lose more weight than normal babies in the post-natal period has been reviewed.
Because of differences in the criteria of weight loss and in the management of the newborn, and because of the faulty construction of control groups, this evidence has been found inconclusive.

The weight loss of babies delivered by Caesarean section to diabetic women has been compared closely with that of babies similarly delivered to nondiabetic women and with babies born spontaneously to non-diabetic women.

When infants of diabetic women are subjected to prolonged fluid deprivation they lose more weight than when fluids are given early, and also lose more weight than infants of non-diabetic women by whichever route these have been delivered.

Infants of diabetic and non-diabetic women delivered by Caesarean section lose similar amounts of weight when nursed under similar conditions.

Infants delivered by Caesarean section to diabetic or non-diabetic women lose more weight over a longer period than infants delivered spontaneously to non-diabetic women. They also regain weight more slowly.

We wish to thank Professor R. W. B. Ellis for his constructive criticism of this paper, Miss A. Brown for assistance in the collection of the original data, Miss P. Johnston and Miss W. Laidlaw for computing, and Miss E. Meiklejohn for secretarial help.

\section{REFERENCES}

Baird, D. (1950). Combined Textbook of Obstetrics and Gynaecology, 5 th ed. Edinburgh.

Cardell, B. S. (1953). J. Obstet. Gynaec. Brit. Emp., 60, 834.

Dunlop, D. M., Davidson, S. and Alstead, S. (1958). Textbook of Medical Treatment, 7 th ed. Edinburgh.

Ellis, R. W. B. (1956). Disease in Infancy and Childhood, 2nd ed. Edinburgh

Farquhar, J. W. (1956). Arch. Dis. Childh., 31, 483.

Furuhjelm, U. (1954). Etudes Néonatales, 3, 93.

Gellis, S. S. (1954). Nelson's Textbook of Pediatrics, 6th ed. London. -, White, P. and Pfeffer, W. (1949). New Engl. J. Med., 240, 533. Gregory, J. (1871). Arch. Gynäk., 2, 48.

Griffith, J. P. C. and Gittings, J. C. (1907). Arch. Pediat., $24,321$.

Grulee, C. G. and Eley, R. C. (1952). The Child in Health and Disease, 2nd ed. Baltimore.

Holmes, B. (1896). Transactions of the Illinois Society for Child Study, 2, 201.

Johnstone, R. W. and Kellar, R. J. (1955). A Textbook of Midwifery, 16 th ed. London.

Kotz, J. and Kaufman, M. S. (1939). J. Amer. med. Ass., 113, 2035.

Naish, F. C. and Edwards, P. W. (1952). Arch. Dis. Childh., 27, 445.

Nelson, W. E. (1954). Textbook of Pediatrics, 6th ed. London.

Price, F. W. (1956). Price's Textbook of the Practice of Medicine, 9 th ed. London.

Rott, F. (1910) Z. Kinderheilk, 1, 43.

Salber, E. and Bradshaw, E. (1954). Hum. Biol., 26, 156.

Smith, C. A. (1951). The Physiology of the Newborn Infant, 2nd ed. Oxford.

Snedecor, G. W. (1956). Statistical Methods, 5th ed. Ames, Iowa. White, P. (1952). Joslin's Treatment of Diabetes Mellitus, 9th ed. London.

Zweifel, P. (1878). Zbl. Gynäk., 2, 1. 